\title{
GEO-ARQUEOLOGÍA DEL MONUMENTO NACIONAL GUAYABO (MNG), TURRIALBA, COSTA RICA
}

\author{
GEO-ARCHAEOLOGY OF MONUMENTO NACIONAL GUAYABO, \\ TURRIALBA, COSTA RICA
}

\author{
Luis G. Obando* \& Giovanni Peraldo \\ Escuela Centroamericana de Geología, Universidad de Costa Rica \\ *Autor para contacto: lobando@geologia.ucr.ac.cr
}

(Recibido: 16/02/2011; aceptado: 1/06/2011)

\begin{abstract}
The geoarchaeology evaluation of the Monumento Nacional Guayabo (M.N.G.) shows the following problems: the water, with $\mathrm{pH} 5,5-6,0$ or 7, flows over the rocks paths, it is a chronic problem, the cause could be springs, aqueduct collapse, poor soil infiltration. The low $\mathrm{pH}$, could cause colored precipitates. The abundant flora, like lichens, have covered the rock and other geoarchaeological features. The lichens could damage the lithic and glyphs.

The geological study, shows regional and big landslides, but the M.N.G. seems to be stable and there are not in the Monument itself.

The petrography shows a basaltic-andesite rocks with glass matrix. It means that the rock is easily eroded. The fluidal texture produces natural laminations. It is means no harmful rocks just it is a natural feature.

Key words: geoarchaeology, petrography, basaltic-andesite, Turrialba volcano, mud flows, landslices, lithology

RESUMEN: La evaluación geoarqueológica del Monumento Nacional Guayabo (M.N.G.) mostró, lo siguiente: problemas con aguas de inundación pasiva, con pH bajos de 5,5-6,0 hasta 7, en las calzadas, lo cual parece ser un problema crónico, la causa puede ser descargas de manantiales, colapso del acueducto o pobre infiltración de suelo. Proliferación descontrolada de líquenes que ya han cubierto por completo rocas y objetos arqueológicos, probablemente los líquenes son encostrantes deteriorando la lítica.

Desde el punto de vista geodinámica externa, se han observado deslizamientos de tierra y roca. El sitio M.N.G, no tiene evidencia de deslizamientos recientes y se encuentra asentado en un área estable.

La petrografía muestra que las rocas son andesitas-basálticas con mucho vidrio en la matriz y de textura fluidal, lo cual generan laminaciones y lajamientos, tales rasgos no deben ser necesariamente interpretados como lítica en deterioro. Palabras Clave: petrografía, andesita-basáltica, geoarqueología, volcán Turrialba, lahares, deslizamientos, litología, líquenes.
\end{abstract}




\section{GENERALIDADES}

El Monumento Nacional Guayabo se encuentra en las laderas del volcán Turrialba. El sitio se ha asentado sobre depósitos volcánicos procedentes de dicho volcán. Los depósitos observados son lavas andesíticas basálticas ricas en potasio, basaltos y andesitas de alto contenido de $\mathrm{K}_{2} \mathrm{O}$ y lahares (flujos de barro) (Alvarado, 2005; Mora et al., 2004). Los flancos del macizo están constituidos por coladas de lava relativamente recientes cubiertas por tefras (cenizas y lapillis). En la cima, adyacente a los cráteres y hasta en las faldas; han sido identificados depósitos de oleadas y flujos piroclásticos (Soto, 1988).

Respecto a la geomorfología, el volcán Turrialba, comparte la misma base que el volcán Irazú. Es el más oriental de la cordillera Volcánica Central, pues su posición se sale del alineamiento general de la cordillera. La cima está constituida por una caldera o depresión dentro de la cual se ubican los tres cráteres principales (Alvarado, 2005). De acuerdo a Barquero \& Rojas (2010), se presenta actividad fumarólica con emisiones de gases producto de la actividad exhalativa del cráter activo y sismos relacionados con la desgasificación.

Paniagua \& Soto (1986), indicaron que el peligro volcánico está relacionado con:

- Caída de piroclastos. ticas.

- Explosiones dirigidas y emisiones piroclás-

- Emisión de oleadas piroclásticas y explosiones freáticas asociadas.

- Avalanchas volcánicas.
- Flujos de lodo.

- Emisión de coladas de lava.

- Apertura de nuevos focos de emisión.

- Lluvia ácida y dispersión de gases.

- Actividad fumarólica y sísmica.

- Posibles erupciones en los próximos dos siglos.

\section{RECONOCIMIENTO GEOLÓGICO REGIONAL}

\section{Información histórica}

Sobre los alrededores del Monumento Nacional Guayabo, existe información histórica que evidencia una geodinámica externa activa por inestabilidad de laderas. Se reportan deslizamientos históricos en Guayabo y en La Laja (Cuadro 1).

El reconocimiento geológico de campo se llevó a cabo con el fin de identificar posibles amenazas por reptación y deslizamientos superficiales. Este reconocimiento se basó en el mapa fotogeológico e involucra las visitas a las localidades de Guayabo Arriba, río Torito, Colonia Guayabo y San Diego, entre otras.

Hacia el norte del M. N. Guayabo, cerca de la población de Guayabo Arriba se pueden observar formas erosivas que corresponden a deslizamientos relativamente recientes (fig. 1, coordenadas Lambert 218,80-568,50). Son formas erosivas con escarpe filoso (límite árboles-pasto).

En la figura 2 (Quebrada Lajas, en coordenadas Lambert 219,45-568,80), se pueden observar formas que corresponden a reptación severa del

Cuadro 1

Deslizamientos históricos en las cercanías de Guayabo, (Peraldo \& Rojas, 2000)

\begin{tabular}{cccc}
\hline Año-mes-día & Lugar & Dimensiones & Elementos de riesgo \\
\hline 1903 & Guayabo & Grande & Vía férrea. \\
$1908-12-27$ & Guayabo & & Vía férrea. \\
$1910-05-04$ & Guayabo & Pequeños & $\vdots ?$ \\
$1936-11-27$ & La Laja (Río Lajas) & Grande & Vía férrea \\
\hline
\end{tabular}




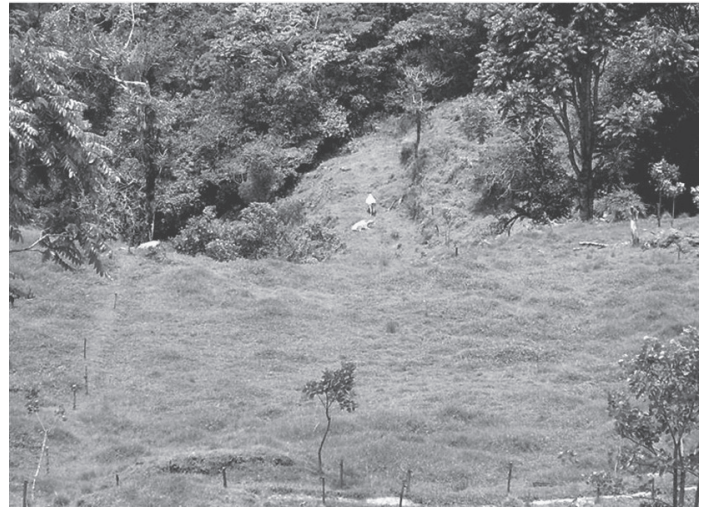

Fig. 1: Forma erosiva con escarpe filoso (límite árboles-pasto), podría corresponder a un deslizamiento relativamente reciente. Un km. NE de la población de Guayabo Arriba.

terreno y fracturas de la ladera que pueden relacionarse con activación de deslizamientos de pequeña escala, definiendo coronas laterales.

El deslizamiento Torito (fig 3, coordenadas Lambert 219,7-569,25) pone en peligro la actividad agrícola del área y la ruta hacia Torito. Además, dado que el material removido fue lanzado hacia el río cercano, se han producido consecuencias inmediatas relacionadas con alteración del equilibrio hídrico aguas abajo.

EL deslizamiento de la figura 4, coordenadas Lambert 220,15-569,10, presenta un pequeño escarpe de deslizamiento. Se observa un proceso

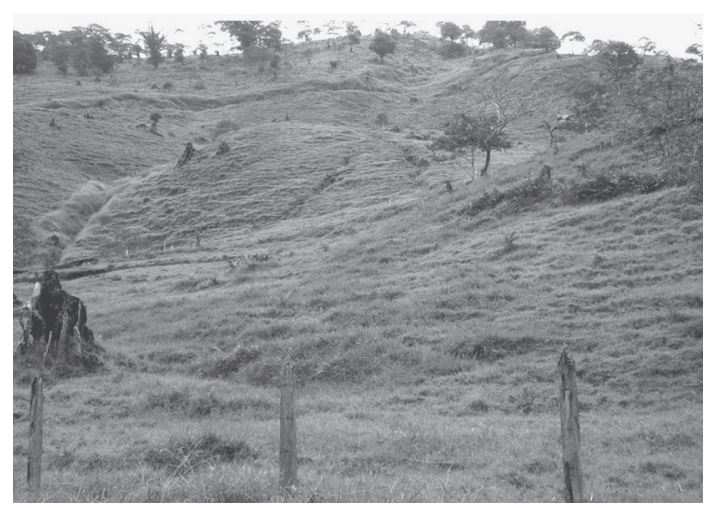

Fig. 2: Formas erosivas cerca de la Quebrada Lajas, se observa reptación severa (ondulaciones irregulares) y fracturas en la ladera.

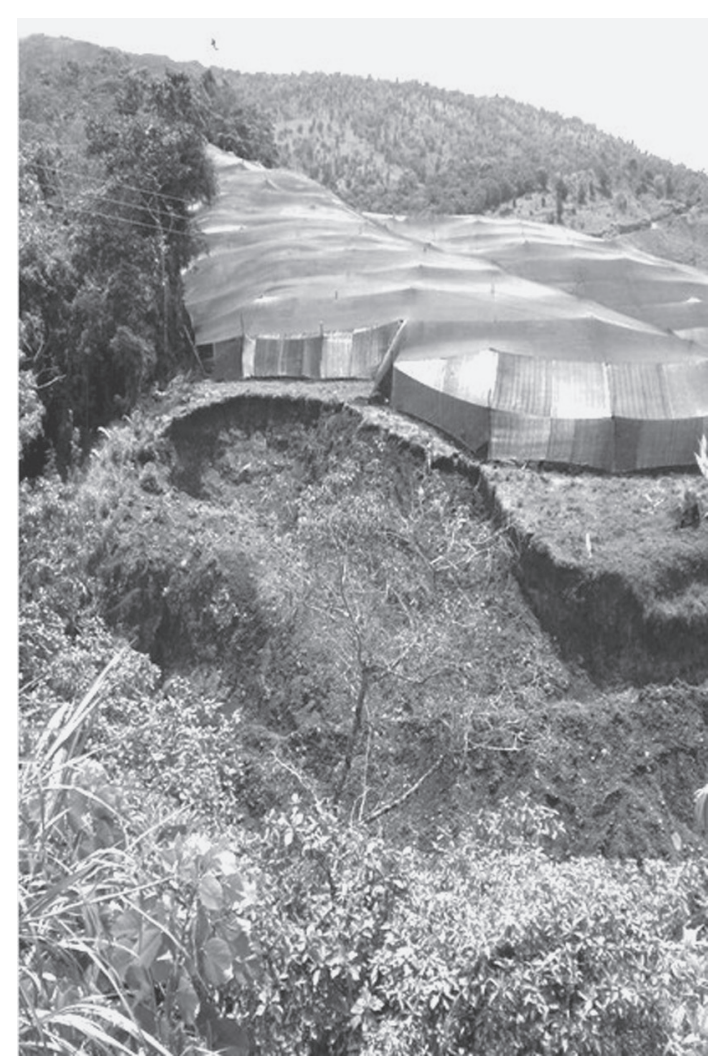

Fig. 3: Deslizamiento Torito. El material cayó en el camino y posteriormente, durante la limpieza del mismo, fue lanzado al río Torito.

de reptación moderada (irregularidades del pasto, arriba en la foto), que pudo influir en la inestabilidad del talud.

Hacia el sur del sitio arqueológico, el río Reventazón, las formaciones geológicas (Formación Uscari, Formación Río Banano) muestran signos de una fuerte inestabilidad del terreno. Es bien sabido que hacia las laderas del río Reventazón, existen megadeslizamientos crónicos como los de Jesús María, río Guayabo, Ánimas, Peralta, Torito, Río Jabillos, entre otros.

Entre Turrialba, el río Guayabo y San Antonio, la inestabilidad reciente del terreno es notoria pues el visitante podrá observar como la carretera hacia el sitio arqueológico, evidencia signos típicos de deslizamiento del terreno. 


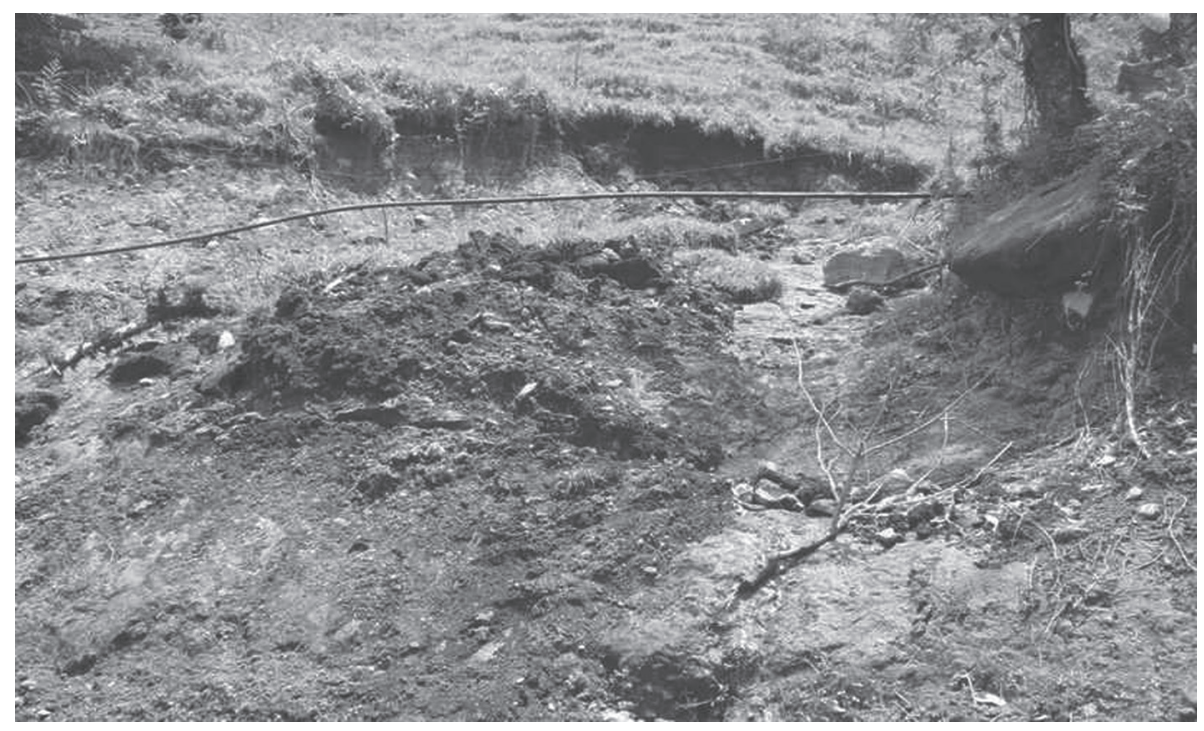

Figura 4: Deslizamiento de pequeña escala.

En el estudio fotogeológico llevado a cabo en las cercanías del M .N. Guayabo (fig.5) se puede observar que los deslizamientos y escarpes se encuentran a lo largo del río Lajas, río Guayabo, río Guayabito y las quebradas aledañas a San Diego. Nótese que en relación con M. N. Guayabo, los deslizamientos y escarpes están muy desarrollados. Lo anterior ha producido una zona amplia de erosión y depositación de sedimentos, causado por el proceso erosivo de aguas arriba, lo cual se puede ver al sur de la Colonia Guayabo.

En términos generales, parece ser que el sitio arqueológico mismo, no presenta signos de deslizamientos de tierra o roca recientes. Y por lo menos hoy día, no hay amenaza directa de los deslizamientos descritos al norte y sur del M. N. Guayabo.

\section{GEOARQUEOLOGÍA DEL MONUMENTO NACIONAL GUAYABO}

El análisis geológico del sitio arqueológico involucraba la cartografía de los rasgos geológicos, petrografía y de escorrentía superficial. Estos rasgos geoarqueológicos se muestran en el mapa geológico (Fig. 6).

\section{Basamento rocoso}

Entiéndase como basamento rocoso, el substrato geológico basal. En este caso dicho basamento está compuesto por un lahar, esto es, un flujo de barro, clasificado como un limo elástico gravoso con arena de plasticidad extremadamente alta. Su color es café amarillento claro. Esta matriz, poco consolidada, envuelve fragmentos volcánicos variados color gris claro a rojos, típicos del volcán Turrialba. Esta litología tiende a ser impermeable o bien, a filtrar agua lentamente debido su matriz limosa. Ello puede provocar escorrentías superficiales, que en dependencia de la intensidad de las lluvias, pueden ser muy erosivas, las cuales dejan con el tiempo canales profundos. Esta morfología es observable en el patrón de drenaje del área. Otro rasgo típico de este tipo de litologías poco infiltrantes, es la aparición de charcas o lagunas efímeras de tamaño variado (Fig .6).

Los lahares se han observado en los caños de desagüe, en la carretera principal de acceso al Monumento (fig 6, fig 7 y fig 8), al borde sur de la calzada Caragra (dentro del Monumento) y en el cauce de la quebrada Chanchera. 


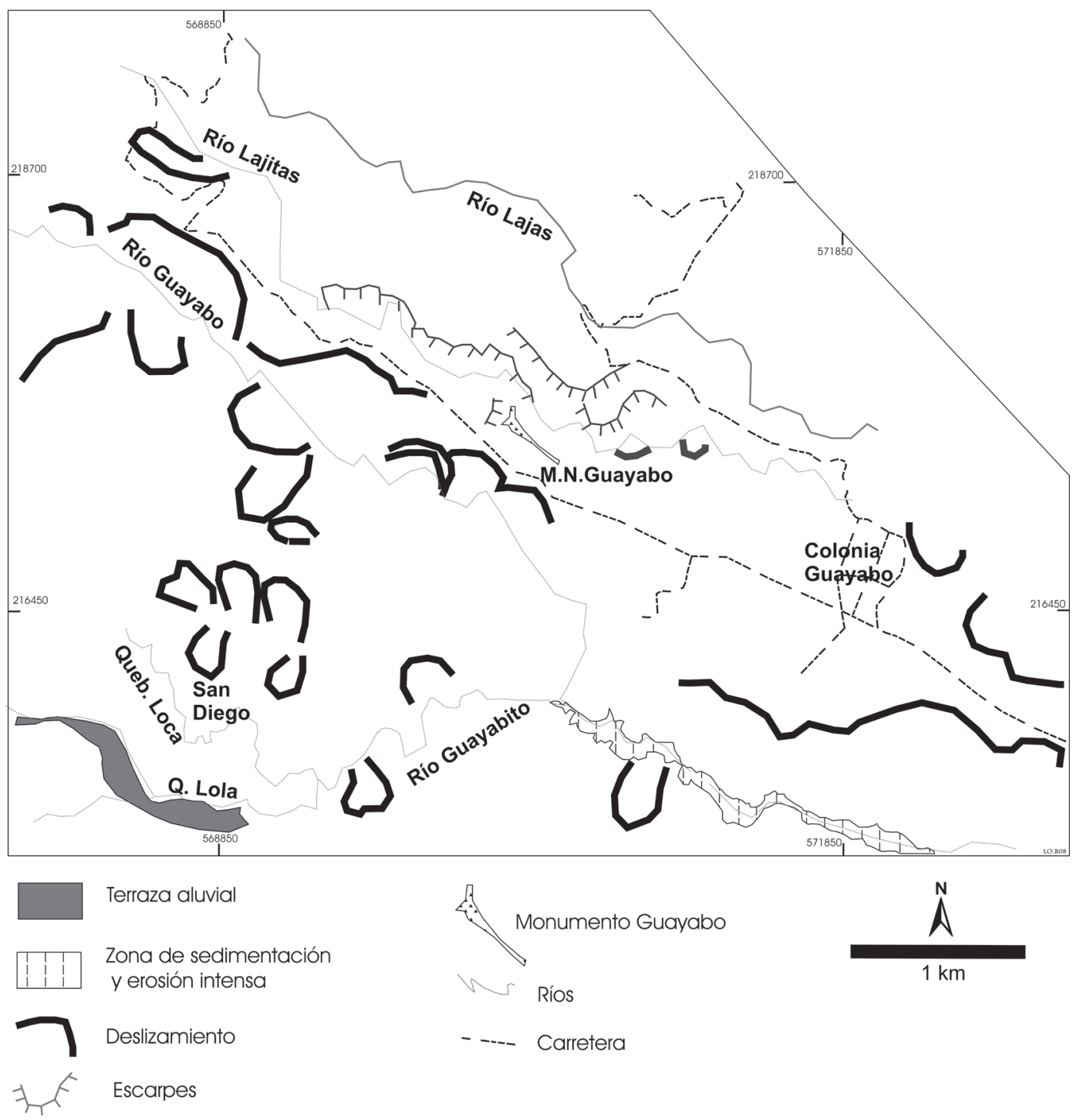

Figura 5: Mapa esquemático de la geodinámica externa, se muestran los deslizamientos y escarpes aledaños al M. N. Guayabo.

Dado que el M. N. Guayabo fue edificado sobre este basamento poco permeable, se hace necesario un mantenimiento constante de los sistemas de drenajes antiguos y recientes, a fin de evitar empozamientos de las aguas y posible erosión del basamento, esto, si la escorrentía superficial llega a ser violenta.

\section{Litología}

La observación macroscópica de la lítica que compone las rocas del M.N.Guayabo, muestra al menos tres tipos de rocas volcánicas, aunque el color es el mismo, gris claro, pero la textura petrográfica es diferente. Todas las rocas son lavas 


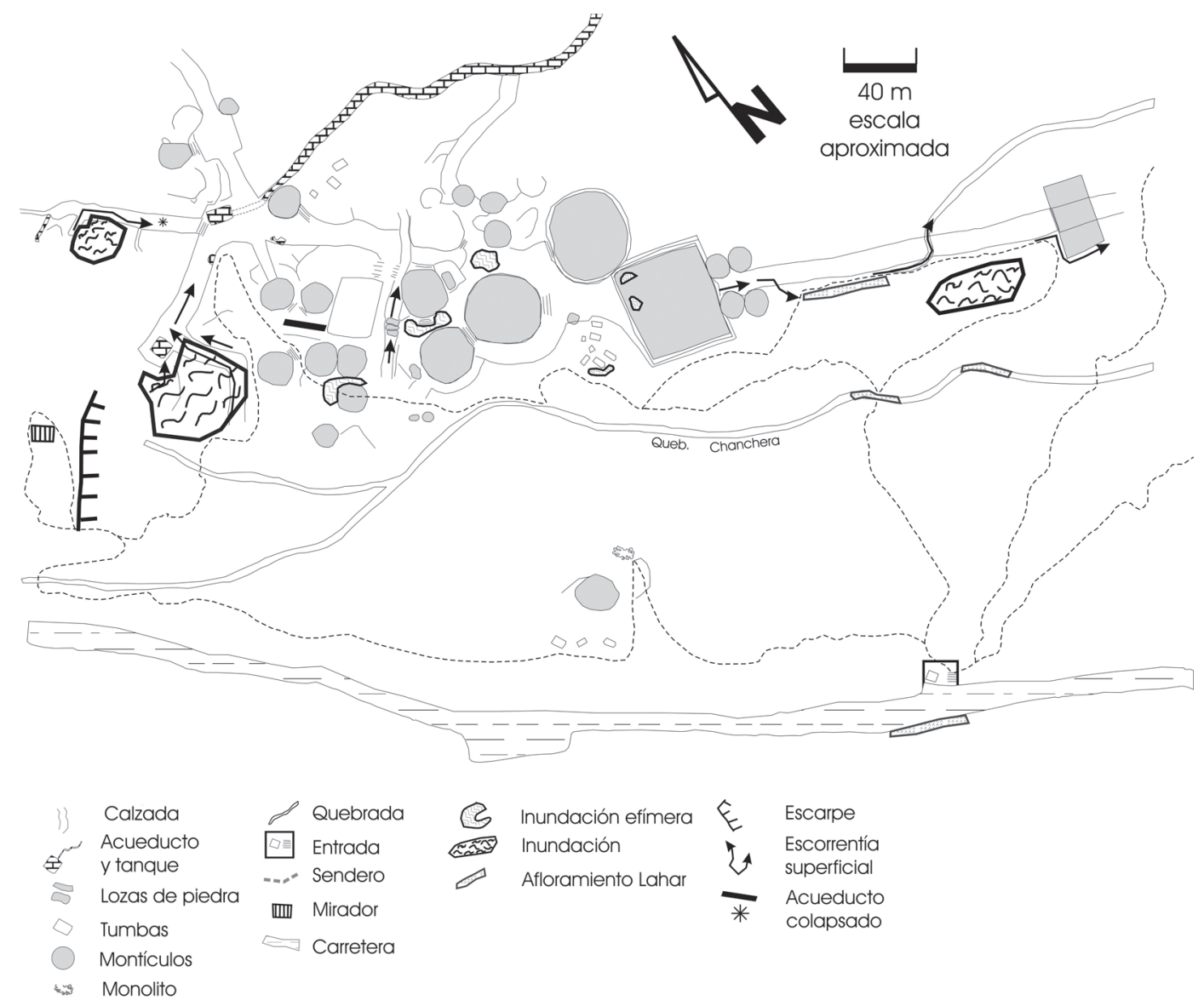

Fig. 6: Cartografía de rasgos geoarqueológicos, Monumento Nacional Guayabo.

andesíticas porfiríticas, con variación en la granulometría de los cristales, varían entre fino y gruesa (tamaño menos de $1 \mathrm{~mm}$ a $2 \mathrm{~mm}$ ). Sin embargo, la observación e identificación de la lítica para su correcta identificación se hace difícil debido a la cobertura vegetal (principalmente líquenes) que poseen estas rocas. Los líquenes han proliferado, en parte debido a la humedad y fuerte iluminación presentada en el sitio arqueológico debido a la ausencia de árboles y arbustos, los cuales pueden proporcionar sombra.

Macroscópicamente las rocas son andesitas porfiríticas con fenocristales de plagioclasa, color gris claro. Según Kussmaul et al. (1982), las vulcanitas del Turrialba, químicamente son basaltos andesíticos, andesitas basálticas a andesitas. La petrografía, muestra andesitas basálticas con augi- ta que pueden presentar una textura: hipocristalina glomeroporfirítica seriada fluidal, con algunas vesículas parcialmente rellenas. Presenta fenocristales de plagioclasa, augita, olivino, poco hipersteno y microfenocristales de magnetita dentro de una matriz intersertal. Las acumulaciones de fenocristales consisten principalmente de augita.

Un hecho que debe resaltarse, es que las rocas presentan textura fluidal, lo cual se manifiesta macroscópicamente como laminaciones, esto hace que las rocas se rompan en forma de lajas de tamaños variados (fig. 9 a 13), sin embargo, la fuerza requerida, en algunos casos, para romper una laminación de este tipo puede ser importante.

Por otra parte, dado que la petrografía muestra mucho vidrio volcánico, el cual es relativamente fácil de erosionar, la limpieza de la roca, en caso 


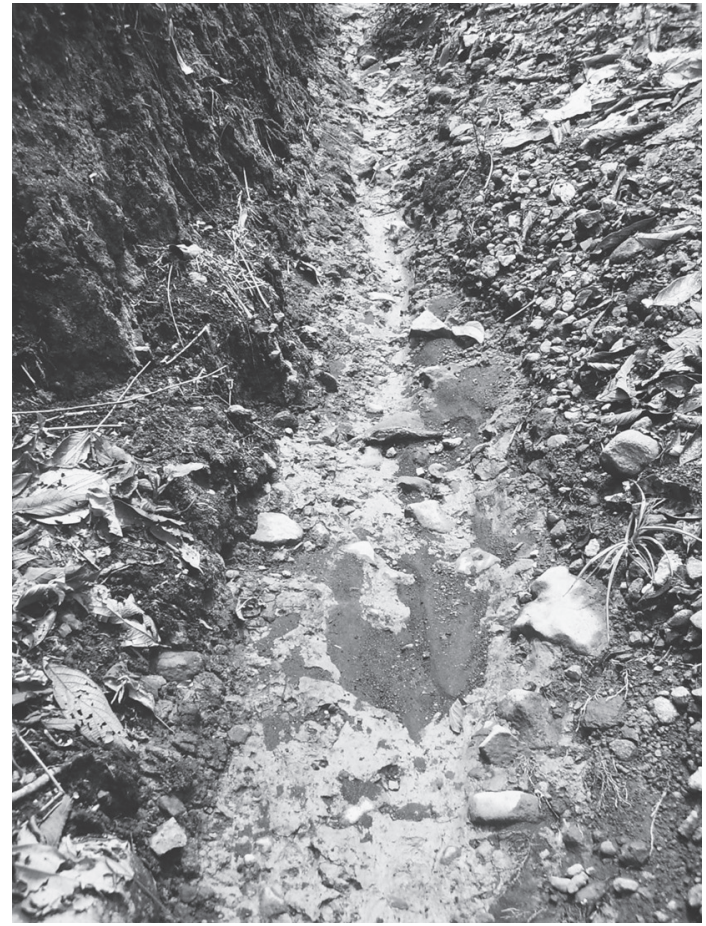

Fig. 7: Caño de desagüe que muestra el afloramiento de lahar, color café claro. Sobre la carretera de acceso al sitio de Guayabo.

de ocurrir, no debe hacerse por frotación severa (cepillo de raíz o acero), de lo contrario, la roca puede erosionarse. Por ejemplo, la limpieza de petroglifos, utilizando este sistema no es nada recomendable.

Cabe indicar, que las rocas observadas durante el trabajo de campo, se encuentran poco o nada meteorizadas.

\section{Escorrentía superficial y agua empozada}

La escorrentía superficial se muestra como agua persistente que discurre por gravedad, mostrando un flujo laminar o bien como una inundación lenta y pasiva. Este fenómeno es notorio y representa una zona de descarga de agua. Considérese aquí solamente el agua no propia de los acueductos. En el M. N. Guayabo, se observa la escorrentía superficial tanto sobre la calzada, al lado oeste del mismo (fig. 6, fig. 9 y figs 14 a

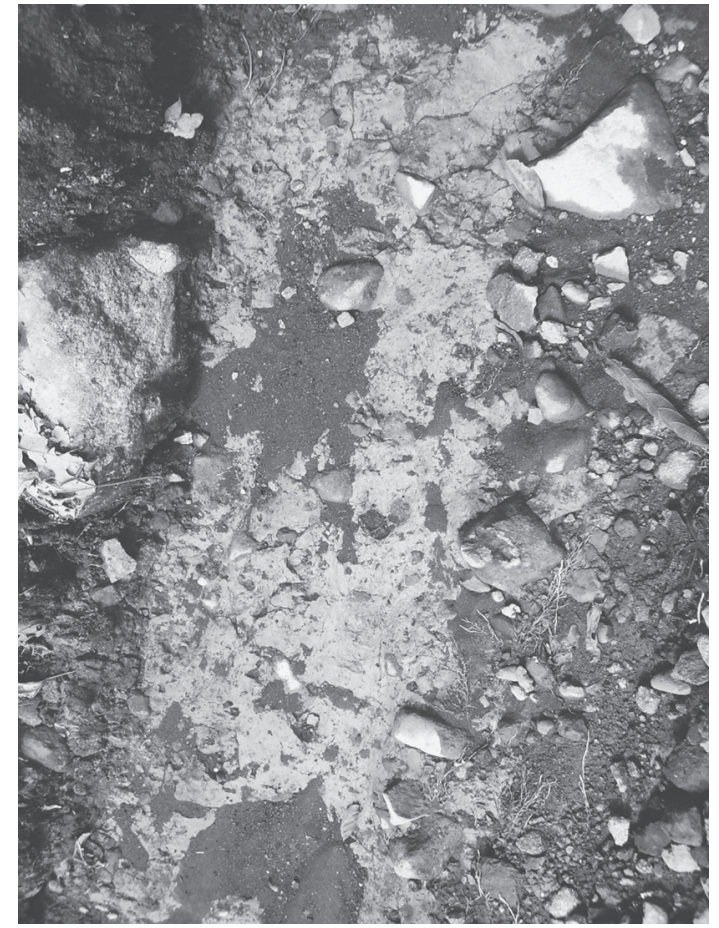

Fig. 8: Detalle del lahar que aflora sobre la carretera de acceso.

15), como en los canales de desagüe artificiales que atraviesan la calzada Caragra (hacia el este).

La medición del $\mathrm{Ph}$ mostró valores de acidez de 5,5, 6,0 hasta neutros 7,0, quizás este valor no sea dramático para causar un daño a la roca, pero los $\mathrm{Ph}$ bajos, sí pueden disolver carbonatos o bien óxidos de hierro o manganeso que pueden provocar la aparición de precipitados sobre la lítica o algas, los cuales al depositarse dan pátinas que pueden manchar las rocas (machas rojas, negras o blancas a grises). Localmente, se observó tonos rojizos en esta agua de escorrentía, producto de óxidos disueltos o bien colorantes no determinados.

Como ya es conocido, el agua que discurre sobre la calzada inunda la misma y procede de la zona boscosa del oeste. Esta situación es ya un problema conocido y crónico, pues se había reportado desde 1986, cuando el CATIE, elaboró un plan de manejo para el desarrollo del monumento (Troyo \& Garnier, 2002). Recientemente, fue reportado por Narváez (2007) y la presente investigación lo corrobora. 


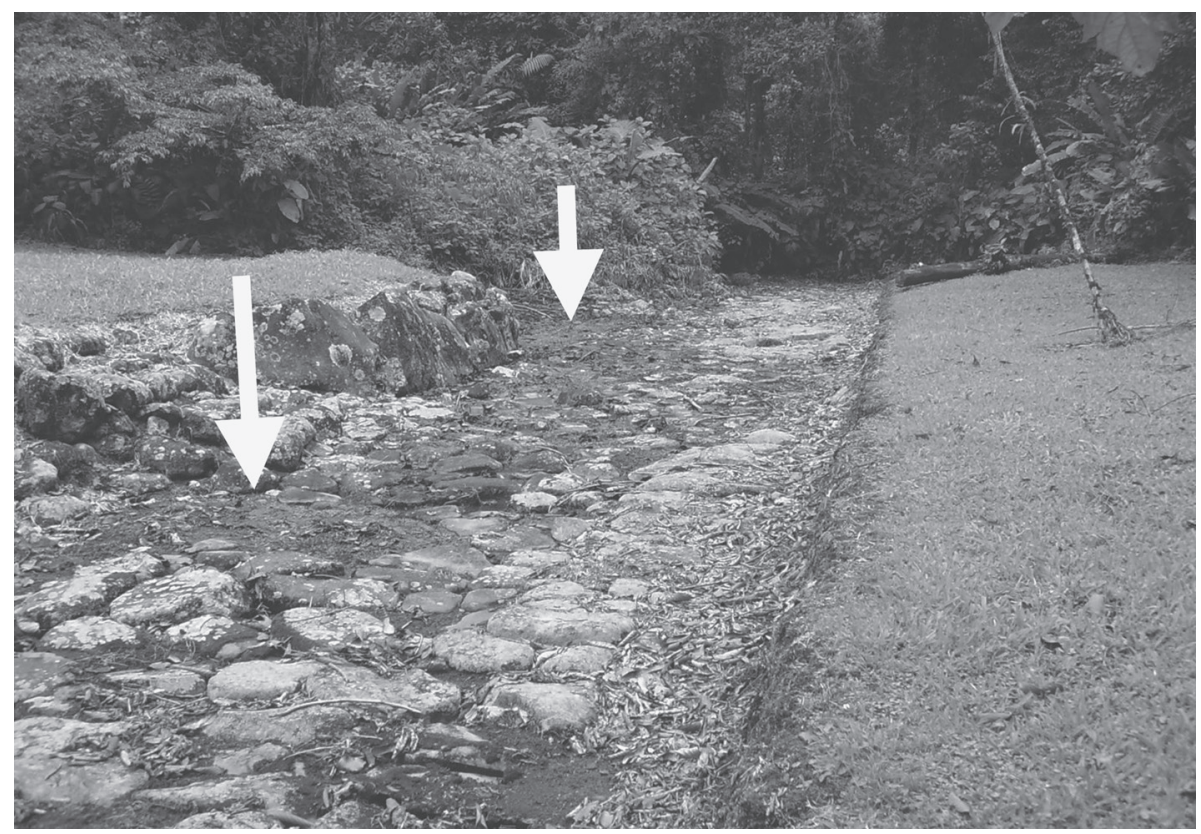

Fig.. 9: Calzada noroeste. Esta calzada está formada por lajas de andesitas. Al lado izquierdo sobre la calzada, se observa aguas de escorrentía superficial (tonos más oscuros indicado por las flechas).

Entre las posibles causas de las descargas de agua, se encuentran la pobre infiltración del suelo, el colapso del acueducto, los manantiales al pie del escarpe (mirador) o la ruptura del cauce de la quebrada Chanchera.

\section{Agua empozada}

Pequeños pozos de agua efímera, se pueden observar alrededor de los montículos, sobre las calzadas (fig.6). De acuerdo con las conversaciones sostenidas con los guardaparques, se ha observado agua empozada directamente al sur de la Calzada Caragra (fig.6). Esta agua se presenta después de aguaceros y puede permanecer un buen tiempo. Visualmente, la laguna permanece oculta a la vista debido a la densa vegetación.

\section{Escarpe}

Este rasgo geomorfológico se localiza al pie del "mirador" (fig. 6), se aprecia como un rasgo de dirección aproximada norte-sur al pie de un cerro o colina, de composición geológica desconocida, ya que no se observan afloramientos de roca. Debido a la ausencia de un mapa topográfico detallado, no es posible definir claramente sus rasgos geomórficos. Sin embargo, conociendo las características geológicas regionales, se puede inferir las siguientes posibilidades: a) que la colina o cerro sea una colada de lava y b) que el escarpe sea producto de un antiguo deslizamiento que haya afectado el basamento lahárico. En este último caso, dicho deslizamiento, en caso de que lo sea, no es activo y no parece haber afectado la infraestructura. Sin embargo, esto no es más que una hipótesis de trabajo y debe ser comprobada.

\section{Vegetación y hormigas}

Dado que el M. N. Guayabo no posee vegetación arbórea o arbustiva y zacates altos, la iluminación y las condiciones de humedad han sido las óptimas para la proliferación de líquenes, entre otros. Estos líquenes, como se indicó antes, han proliferado demasiado, al punto de impedir, en algunos casos, 


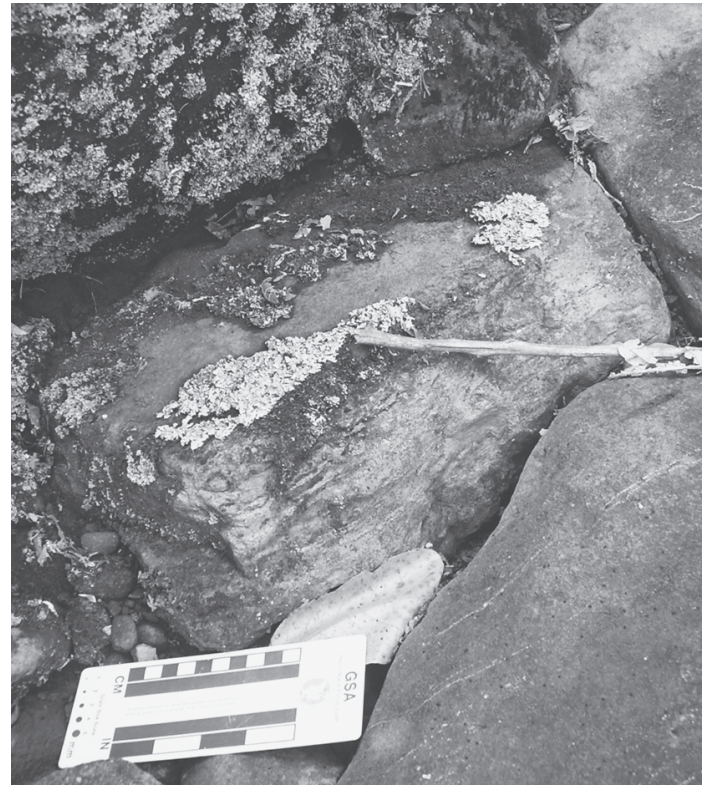

Fig. 10: Obsérvese las laminaciones paralelas de la roca (líneas blancas y tendencias horizontales).

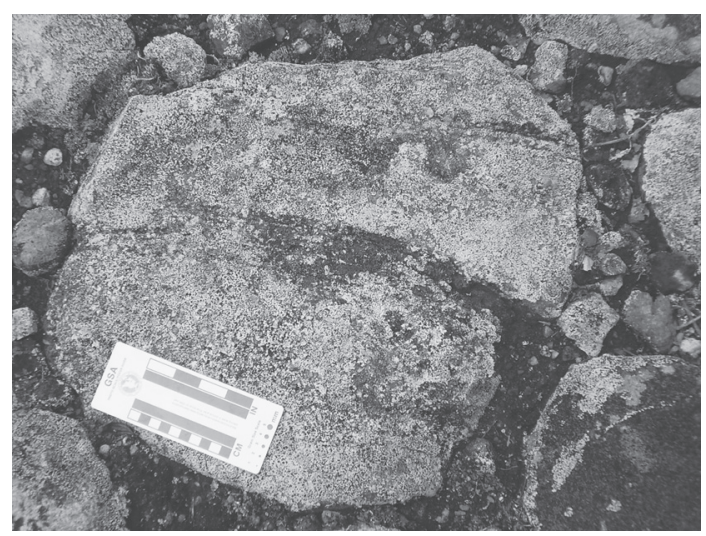

Fig. 12: Obsérvese las laminaciones paralelas en la roca, que provocan claras divisiones en forma de lajas. En esta foto se puede observar también la fuerte colonización de líquenes (manchas blancas) que recubren la roca por completo.

la observación de la mineralogía de la lítica, lo cual hace imposible su identificación macroscópica.

La petrografía señala la presencia de vidrio volcánico, lo cual es común en la Cordillera Volcánica. Dicho vidrio es relativamente suave y fácil de erosionar, si los líquenes fueran del tipo crustosos saxícolas endolíticos (aspecto de costra que prefiere las rocas) estos se adhieren fuerte-

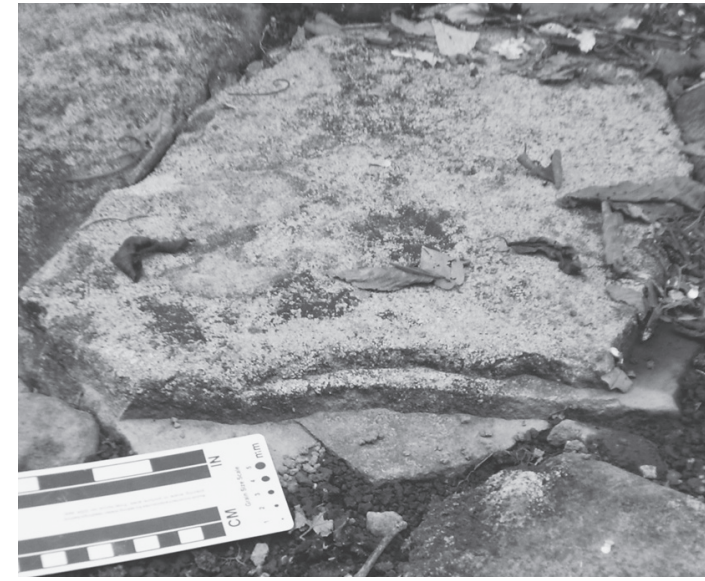

Fig. 11: La textura fluidal (el alineamiento paralelo de minerales), causa la tendencia de las rocas andesíticas a producir un lajamiento persistente.

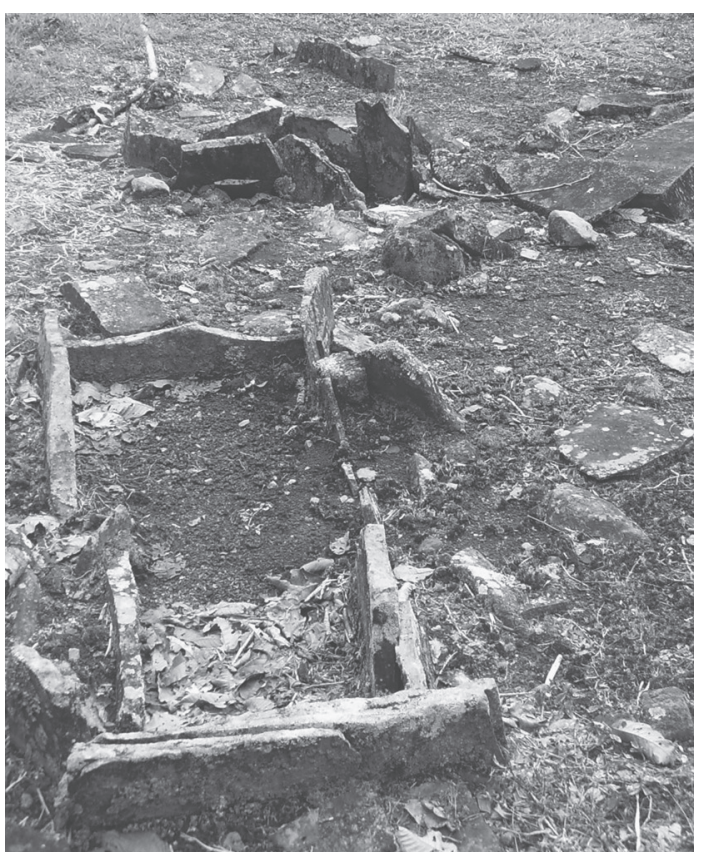

Fig. 13: Tumbas confeccionadas con lavas andesíticas lajeadas. Nótese en la parte inferior de la foto el fracturamiento típico en lajas.

mente al substrato rocoso y atacan la roca por medio de ácidos y sustancias liquénicas (Ladd, 1998; Torbjørg \& Stefan, 2005). Esto significa que estos organismos se han encostrado y su posible remoción podría dar problemas a las rocas. 


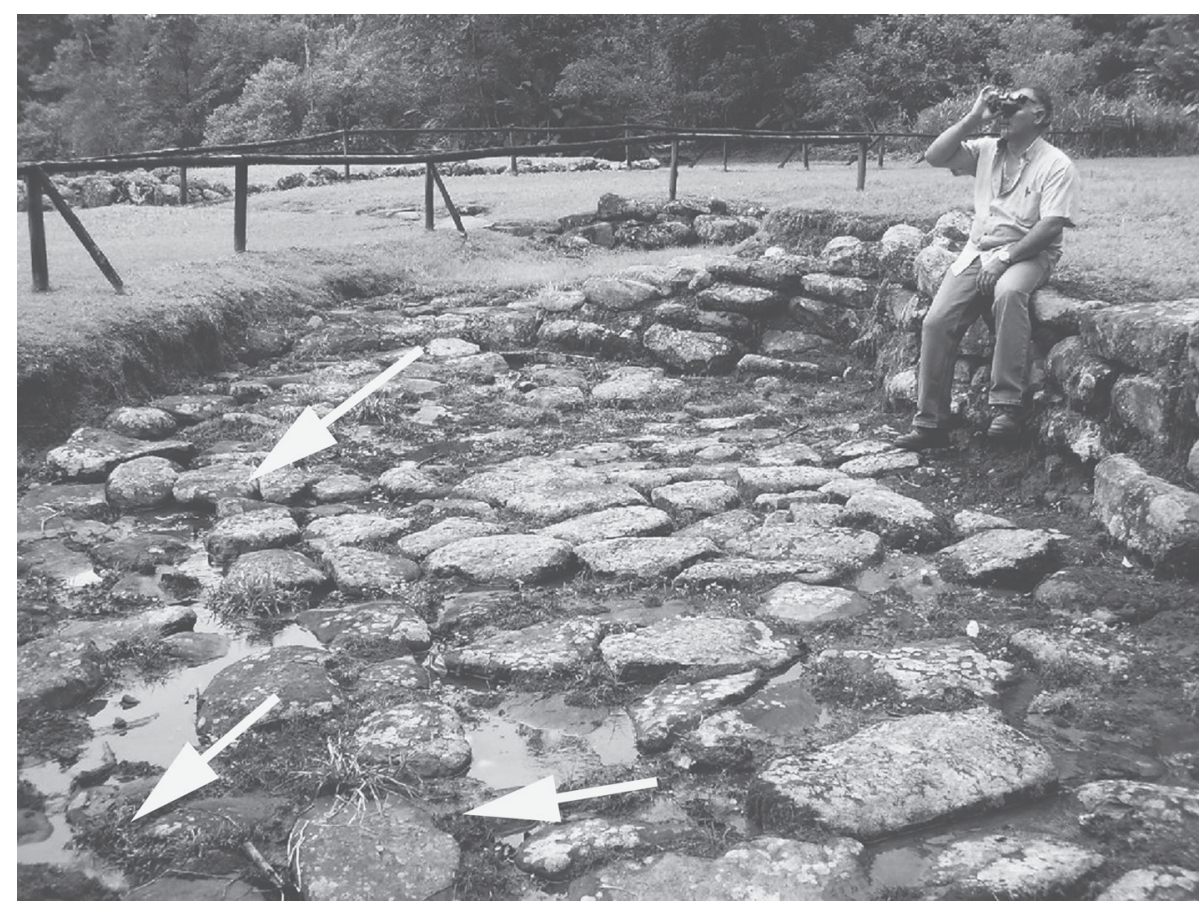

Fig. 14: Agua de escorrentía superficial que discurre sobre la calzada, las flechas indican la dirección de flujo. Al fondo, entre la vegetación, se localiza la salida del sendero hacia el sitio arqueológico.

Respecto a los hormigueros, estos son comunes y fáciles de observar, son zompopas que tienen nidos localizados casi por todo el Monumento, pero dominan la parte central. Su efecto directo sobre las rocas no es perceptible, pero pueden desestabilizar parcialmente montículos u otros montajes, debido a las excavaciones de galerías. La aparición de tales insectos ha sido noticia por parte de periódicos nacionales, por ejemplo Carvajal (2008), Ponchner (2009), así como la investigación de insecticidas para erradicar las hormigas zompopas, (Malavassi, 2010).

\section{ALGUNAS RECOMENDACIONES}

En términos generales, parece ser que el sitio arqueológico no presenta signos de deslizamien- tos de tierra recientes, pese a que regionalmente si existen.

Se requieren estudios hidrogeológicos con el fin de cartografiar manantiales, determinar niveles freáticos, entre otros.

El control de la aguas, es prioritario. Se debe controlar la escorrentía superficial dándole un mantenimiento permanente al sitio, a fin de evitar las inundaciones. Para ello es recomendable consultar con el profesional correspondiente y de esta manera realizar los diseños pertinentes de control de aguas.

Es necesario confeccionar y publicar un mapa topográfico de alto detalle que abarque la finca completa, no solo para ubicar en él la infraestructura, sino también para determinar las pendientes del terreno y de este modo, poder diseñar una red de drenaje a fin de lograr el control eficiente de la escorrentía superficial. Por otra 


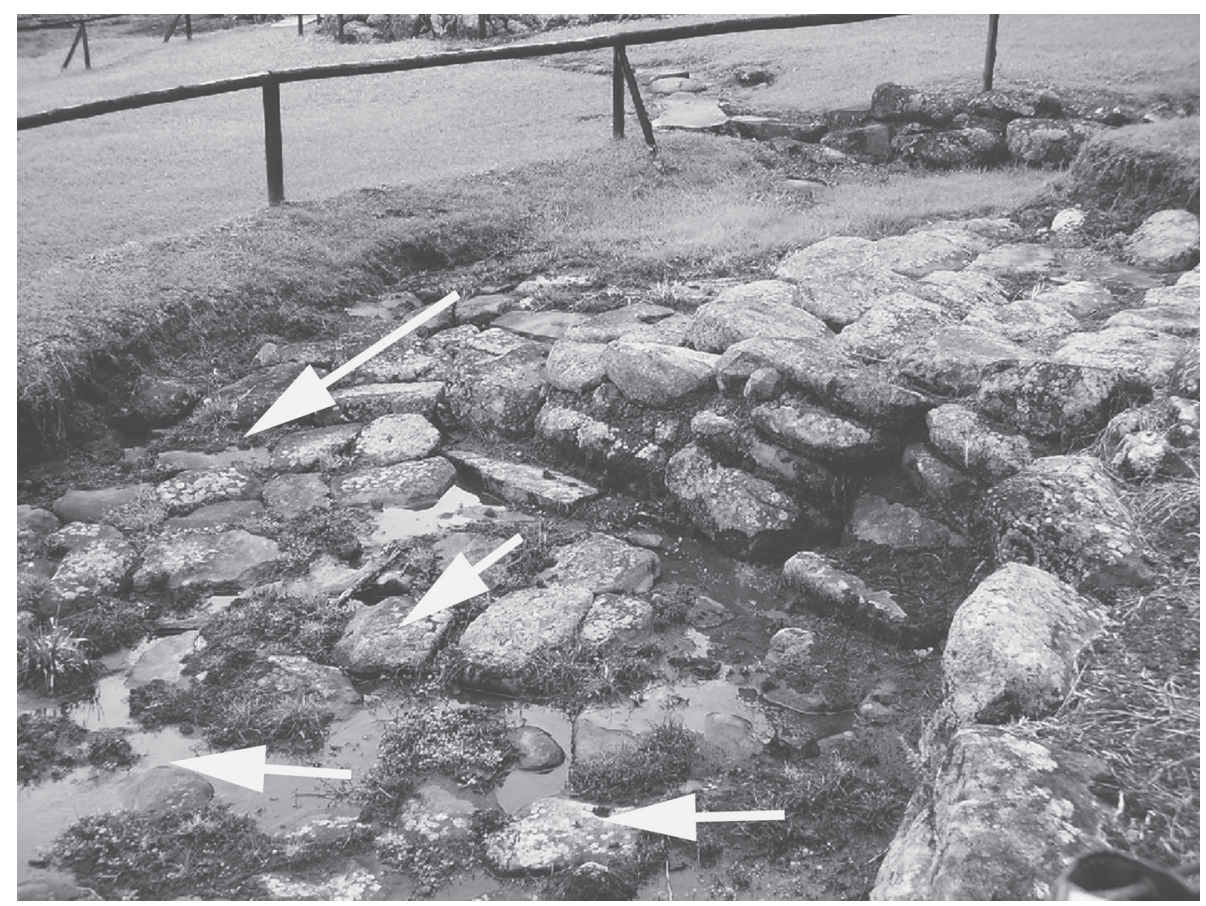

Fig. 15: Detalle de la foto 14. Agua de escorrentía superficial. Las flechas señalan el flujo de agua.

parte, se necesitará cartografiar en dicho mapa, los posibles manantiales, líneas isofreáticas, piezómetros, líneas geofísicas, o los datos producto de futuras investigaciones.

Petrográficamente, la roca es una andesita cuya matriz posee vidrio volcánico, el cual es fácilmente erosionable. Esto significa que la roca no debe limpiarse con abrasivos, como por ejemplo, lijas, cepillos con cerdas de hierro, etc., o sustancias químicas que reaccionen con el sílice del vidrio volcánico.

Se hace necesario consultar con un especialista químico, con especialidad en el ramo de la conservación de líticos, a fin de elaborar los estudios correspondientes para la conservación de la lítica del M. N. Guayabo.

Se debe controlar la proliferación de líquenes y consultar con un especialista para determinar si estos son crustosos saxícolas endolíticos, ya que estos se adhieren fuertemente al substrato rocoso y producen ataques químicos a la roca.

\section{AGRADECIMIENTOS}

Se agradece a la Arqueóloga Elisenda Coladán, Proparques por la ayuda brindada y la coordinación de la visita con los personeros del sitio arqueológico Guayabo, al Dr. Siegfried Kussmaul, por la petrografía y a la Licenciada Geóloga Ana Lucía Valerio (Museo Nacional de Costa Rica) por la revisión del manuscrito.

Trabajo e informe realizado sin fines de lucro por la Escuela Centroamericana de Geología a solicitud de Proparques, en el año 2007. Para esta publicación, tanto los mapas como las observaciones de campo, se actualizaron en el año 2010. 


\section{REFERENCIAS BIBLIOGRÁFICAS}

ALVARADO, G., 2005: Costa Rica: land of volcanoes.- 175 págs. EUNED, San José.

BARQUERO, R. \& ROJAS, W., 2010: Resumen actividad sísmica volcánica en Costa Rica durante, 2009.- Rev. Geol. Amér. Central, 42:127-134.

CARVAJAL, E., 2008: Zompopas devoran el monumento de Guayabo.- Periódico Al Día, http://www.aldia.cr/ad_ee/2008/mayo/11/ nacionales $1529387 . \mathrm{html}$ [Consulta: $10 \mathrm{de}$ enero de 2011].

KUSSMAUL, S., PANIAGUA, S. \& GAINZA, 1982: Recopilación, clasificación e interpretación petroquímica de las rocas ígneas de Costa Rica.- Info. Semestral, Julio a Diciembre, Inst. Geog. Nac., San José, 17-71.

LADD, D., 1998: Looking at Lichens.- Missouri Conversationist, 59(10): 8-13.

MALAVASSI, R., 2010: Desarrollan insecticida para erradicar hormigas zompopas.Girasol, 13(43): 14.

MORA, R., RAMÍREZ, C. \& FERNÁNDEZ, M., 2004: La actividad de los volcanes de la Cordillera Central, Costa Rica, entre 19982002.- Rev. Geol. Amér. Central. (Vol. Espec. Vulcanol.), 30: 189-197.

NARVÁEZ, A., 2007: Informe de Visita Técnica al Monumento Nacional
Guayabo.- 22 págs. Proparques [Inf. Interno].

PANIAGUA, S. \& SOTO, G., 1986: Reconocimiento de los riesgos volcánicos potenciales de la Cordillera Central de Costa Rica, América Central.- Ciencia y Tecnología, 10(2): 49-72.

PERALDO, G. \& ROJAS, E., 2000: Catálogo de deslizamientos de Costa Rica, 1772 -1960 .- Info. Semestral, Inst. Geog. Nac., 36: 123-171.

PONCHNER D., 2009: Científico busca salvar a Guayabo de las hormigas.- Periódico Nación/Aldea Global. Publicado: 2009/11/20. http://wvw.nacion.com/ ln_ee/2009/noviembre/20/aldea2164177. html. [Consulta: 10 de enero de 2011].

SOTO, G. J., 1988: Estructuras volcano-tectónicas del Volcán Turrialba, Costa Rica, América Central.V Congreso Geol. Chileno, 8-12 de agosto de 1988, Santiago, Actas, III (I): 163-175.

TORBJØRG, B. \& STEFAN, E., 2005: Fungal Diversity in Rock Beneath a Crustose Lichen as Revealed by Molecular Markers.Microbial Echology, 49:598-603.

TROYO, E. \& GARNIER, J.E., 2002: Acciones para la preservación del sitio Guayabo: consolidación y restauración.- En: TROYO, E. (ed.): Guayabo de Turrialba. Una aldea prehispánica compleja.- 170 págs. Ministerio de Cultura Juventud y Deporte, Centro de Investigación y Conservación del patrimonio cultural, San José. 